\title{
O COMPLIANCE NO BRASIL E A RESPONSABILIDADE EMPRESARIAL NO COMBATE À CORRUPÇÃO
}

http://dx.doi.org/10.21527/2176-6622.2020.53.69-78

Recebido em: 11/5/2019

Aceito em: 26/10/2019

Cintya Nishimura Durães

Bacharel em Direito pelo Centro Universitário Euripedes, de Marília. Especialista em Direito Processual Civil - NCPC pela Unisc. Mestre pela Universidade de Marília (Unimar) com o apoio da Capes Prosup. Advogada. http://lattes.cnpq.br/1912000152159857. https://orcid.org/0000-0002-0562-5689. cnddireito@gmail.com

\section{Maria de Fátima Ribeiro}

Graduação em Direito pela Universidade Estadual de Londrina. Mestrado em Ciências Jurídicas Empresarias pela Pontifícia Universidade Católica do Rio de Janeiro. Doutorado em Direito pela Pontifícia Universidade Católica de São Paulo. Pós-Doutorado em Direito Fiscal/Tributário na Universidade de Lisboa. Curso complementar créditos de Doutorado na Sapienza Università di Roma Facoltà di Economia e Facoltà di Giurisprudenza, Roma - Itália. Professora titular do Programa de Mestrado e Doutorado em Direito e do curso de Graduação em Direito da Universidade de Marília (Unimar), São Paulo. Integra a Diretoria do Instituto de Direito Tributário de Londrina. Professora convidada da Universidade Estadual de Londrina. Tem experiência na área de Direito, com ênfase em Direito Tributário, atuando principalmente nos seguintes temas: direito tributário tributação e desenvolvimento econômico e social, políticas públicas, princípios constitucionais e soberania, extrafiscalidade, direito constitucional e internacional econômico.http://lattes.cnpq.br/5024013963182084. https://orcid.org/0000-0001-8450-9872.professoramariadefatimaribeiro@gmail.com

\section{RESUMO}

No presente artigo aborda-se o compliance no Brasil e a relação deste com a responsabilidade empresarial no combate à corrupção. 0 objeto do estudo concentra-se na compreensão do programa de integridade como instrumento de combate à corrupção no âmbito das pessoas jurídicas. Objetiva-se identificar na legislação nacional como o compliance pode estar presente no âmbito interno das empresas e qual a importância de sua instituição. Destacam-se as características que um programa de integridade deve apresentar, consoante as disposições previstas em lei. Analisam-se quais são as implicações da aplicação do mecanismo nas empresas, bem como os benefícios que são auferidos pela existência do programa. Adota-se para a pesquisa o método dedutivo, com coleta qualitativa de dados bibliográficos. A relevância do tema é evidente diante do cenário global de enfrentamento da corrupção. Constatou-se que a existência de programas de integridade é imprescindível para o enfrentamento da corrupção empresarial.

Palavras-chave: Compliance. Corrupção. Responsabilidade empresarial.

\section{COMPLIANCE IN BRAZIL AND CORPORATE RESPONSIBILITY IN COMBATING CORRUPTION}

\section{ABSTRACT}

This article discusses compliance in Brazil and its relationship with corporate responsibility in the fight against corruption. The object of the study focuses on the understanding of the integrity program as an instrument to combat corruption within the legal entities. The objective is to identify in national legislation how compliance can be present within companies and what is the importance of its implementation. We highlight the characteristics that an integrity program must have, according to the provisions provided by law. We analyze the implications of the application of the mechanism in companies, as well as the benefits that are obtained by the existence of the program. The deductive method is adopted for the research, with qualitative collection of bibliographic data. The relevance of the theme is evident in the global scenario of facing corruption. It was found that the existence of integrity programs is essential to address corporate corruption.

Keywords: Compliance. Corruption. Corporate responsibility.

\section{SUMÁRIO}

1 Introdução. 2 Compliance no Brasil. 3 Responsabilidade empresarial no combate à corrupção. 40 compliance como ferramenta para a redução da corrupção. 5 Empreendimentos nacionais que possuem programa de integridade. 6 Considerações finais. 7 Referências. 


\section{INTRODUÇÃO}

A responsabilidade empresarial no combate à corrupção vem crescendo no mundo todo. Os países têm se comprometido, por meio de documentos internacionais, a buscarem soluções para o problema. Nesse contexto, os ordenamentos jurídicos passam a exigir o desenvolvimento de programas de integridade ou compliance pelas pessoas jurídicas de Direito privado.

No Brasil, com o advento da Lei n. 12.846/2013, o mecanismo ganhou destaque em meio aos negócios empresariais. As empresas têm elaborado programas de integridade em seus âmbitos internos. Diante disso, questiona-se: Quais são os motivos determinantes para que as pessoas jurídicas de Direito privado estejam estabelecendo o compliance em suas atividades?

A positivação do mecanismo no ordenamento jurídico brasileiro significou um passo importante no combate à corrupção na relação entre as empresas e a administração pública nacional ou estrangeira, todavia indaga-se: Como o compliance pode servir para a redução do problema?

As respostas para as perguntas requerem a compreensão dos motivos que levaram o legislador pátrio a positivar normas versando sobre mecanismos de integridade. Desse modo, buscar-se-á entender o que é o compliance no Brasil, como se verifica a responsabilidade empresarial no combate à corrupção e como o compliance pode contribuir para a redução da corrupção.

Demonstrar-se-á como ocorre a aplicação de um programa de integridade por meio de exemplos concretos de empresas presentes no país.

\section{COMPLIANCE NO BRASIL}

O compliance no Brasil ganhou projeção com a Lei n. 12.846/13, tornando-se um mecanismo cada vez mais difundido no meio empresarial. Busca-se, por meio desse instrumento, compelir as pessoas jurídicas de Direito privado a se manterem em conformidade com as normas e regulamentos legais pela adoção de procedimentos internos pautados pela integridade e pela ética.

O conceito de compliance é compreendido como um conjunto de medidas que implicam procedimentos internos no âmbito das empresas visando à conformidade com a lei, isto é, consubstancia-se em um programa de integridade ${ }^{1}$ com o intuito de impedir a prática de atos lesivos à administração pública nacional ou estrangeira.

O compliance tem a função de monitorar e assegurar que todos os envolvidos com uma empresa estejam de acordo com as práticas de conduta da mesma. Essas práticas devem ser orientadas pelo Código de Conduta e pelas políticas da companhia, cujas ações estão especialmente voltadas para o combate à corrupção (UBALDO, 2017, p. 121).

O interesse do setor empresarial no compliance ganhou força em razão do rigor da lei na atribuição de responsabilidade às pessoas jurídicas, cujas sanções são severas. Em contrapartida, a legislação possibilita a atenuação das penalidades caso existam mecanismos e procedimentos internos de integridade, auditoria, incentivo à denúncia de irregularidades, código de ética e conduta (artigo $7^{\circ}, \mathrm{VIII}$ ).

\footnotetext{
Decreto n. 8.420, de 18 de março de 2015. Art. 41. Para fins do disposto neste Decreto, o programa de integridade consiste, no âmbito de uma pessoa jurídica, no conjunto de mecanismos e procedimentos internos de integridade, auditoria e incentivo à denúncia de irregularidades e na aplicação efetiva de códigos de ética e de conduta, políticas e diretrizes com objetivo de detectar e sanar desvios, fraudes, irregularidades e atos ilícitos praticados contra a administração pública, nacional ou estrangeira.

Parágrafo único. O programa de integridade deve ser estruturado, aplicado e atualizado de acordo com as características e riscos atuais das atividades de cada pessoa jurídica, a qual por sua vez deve garantir o constante aprimoramento e adaptação do referido programa, visando a garantir sua efetividade.
} 
Antes de ser elaborada a Lei n. 12.846/2013 diversas empresas já haviam incorporado programas de integridade. A inovação legal serviu como estímulo a esses estabelecimentos por valorizar a cultura organizacional de ética e probidade, destaca Moreira (2018).

Verifica-se que a adoção do compliance demanda o estabelecimento de um padrão ético que consiste em valores escolhidos pela empresa como compromisso diante da sociedade. Ribeiro e Diniz $(2015$, p. 87$)$ avaliam que: "Compliance é uma expressão que se volta para as ferramentas de concretização da missão, da visão e dos valores de uma empresa".

Para Veríssimo (2017, p. 13-14) as providências que devem ser tomadas para a instituição do compliance consistem em estabelecer controles internos com o objetivo de prevenir e identificar atos de corrupção. Além disso, as condutas contrárias ao programa de integridade devem ser punidas, afirma a autora.

A existência de mecanismos destinados a evitar e controlar os atos em desconformidade com a lei pode impedir, por exemplo, a insegurança jurídica, observa Pasold Júnior (2017, p. 99). Desse modo, constata-se a importância da existência de um programa de integridade no âmbito interno das pessoas jurídicas.

Não basta, entretanto, criar o programa de compliance apenas formalmente. Conforme Blok (2017, p. 116), é necessária a realização de treinamento dos funcionários e monitoramento acerca do cumprimento das disposições adotadas, visando à solidificação da prevenção e à diminuição de riscos pela observância dos procedimentos que componham o programa de integridade.

A pessoa jurídica deve conhecer o setor no qual atua, bem como os riscos de sua atividade, levando em conta a sua governança e seus processos internos de decisão. Além disso, a empresa deve identificar seus públicos de interesse, como os parceiros de negócio, sociedade civil, acionistas, empregados, etc., para que sejam avaliados também os níveis de interação com o poder público, em vista dos atos arrolados no artigo $5^{\circ}$ da Lei Anticorrupção (COUTINHO, 2018, p. 54).

Constata-se que o programa de integridade não se limita a identificar riscos que possam se originar na seara interna da pessoa jurídica, vez que podem ser evitados problemas com as escolhas feitas pelo negócio, isto é, de modo preventivo é possível impedir o envolvimento de empreendimentos ou indivíduos ligados à corrupção, preservando-se desse modo a integridade da empresa. 
O compliance quando bem elaborado e observado por todos é uma ferramenta facilitadora na identificação de vulnerabilidades ou riscos para a pessoa jurídica. Existem parâmetros legais ${ }^{2}$ para a avaliação do programa de integridade dentro da empresa, cuja finalidade é verificar o comprometimento da pessoa jurídica com o compliance. Acerca disso Coutinho (2018, p. 56) observa que:

Como não poderia deixar de ser, a avaliação dos citados parâmetros deve ser feita levando em conta a natureza e complexidade das atividades desempenhadas pelas pessoas jurídicas, bem como seu porte e setor de atuação.

A estrutura empresarial influencia diretamente na determinação dos critérios a serem considerados para a verificação da existência e aplicabilidade do programa de integridade. Quanto mais complexa for a organização, mais rígidos serão os padrões de apreciação sobre a efetividade dos mecanismos.

\footnotetext{
${ }^{2}$ Decreto n. 8.420/2015. Art. 42. Para fins do disposto no §4을 do art. 5ㅇ, o programa de integridade será avaliado, quanto a sua existência e aplicação, de acordo com os seguintes parâmetros:

I - comprometimento da alta direção da pessoa jurídica, incluídos os conselhos, evidenciado pelo apoio visível e inequívoco ao programa; II - padrões de conduta, código de ética, políticas e procedimentos de integridade, aplicáveis a todos os empregados e administradores, independentemente de cargo ou função exercidos;

III - padrões de conduta, código de ética e políticas de integridade estendidas, quando necessário, a terceiros, tais como fornecedores, prestadores de serviço, agentes intermediários e associados;

IV - treinamentos periódicos sobre o programa de integridade;

$\checkmark$ - análise periódica de riscos para realizar adaptações necessárias ao programa de integridade;

$\mathrm{VI}$ - registros contábeis que reflitam de forma completa e precisa as transações da pessoa jurídica;

VII - controles internos que assegurem a pronta elaboração e confiabilidade de relatórios e demonstrações financeiros da pessoa jurídica; VIII - procedimentos específicos para prevenir fraudes e ilícitos no âmbito de processos licitatórios, na execução de contratos administrativos ou em qualquer interação com o setor público, ainda que intermediada por terceiros, tal como pagamento de tributos, sujeição a fiscalizações, ou obtenção de autorizações, licenças, permissões e certidões;

IX - independência, estrutura e autoridade da instância interna responsável pela aplicação do programa de integridade e fiscalização de seu cumprimento;

$X$ - canais de denúncia de irregularidades, abertos e amplamente divulgados a funcionários e terceiros, e de mecanismos destinados à proteção de denunciantes de boa-fé;

$\mathrm{XI}$ - medidas disciplinares em caso de violação do programa de integridade;

XII - procedimentos que assegurem a pronta interrupção de irregularidades ou infrações detectadas e a tempestiva remediação dos danos gerados;

XIII - diligências apropriadas para contratação e, conforme o caso, supervisão, de terceiros, tais como fornecedores, prestadores de serviço, agentes intermediários e associados;

XIV - verificação, durante os processos de fusões, aquisições e reestruturações societárias, do cometimento de irregularidades ou ilícitos ou da existência de vulnerabilidades nas pessoas jurídicas envolvidas;

XV - monitoramento contínuo do programa de integridade visando a seu aperfeiçoamento na prevenção, detecção e combate à ocorrência dos atos lesivos previstos no art. 5으 da Lei no 12.846, de 2013; e

XVI - transparência da pessoa jurídica quanto a doações para candidatos e partidos políticos.

$\S 1$ Na avaliação dos parâmetros de que trata este artigo, serão considerados o porte e especificidades da pessoa jurídica, tais como:

I - a quantidade de funcionários, empregados e colaboradores;

II - a complexidade da hierarquia interna e a quantidade de departamentos, diretorias ou setores;

III - a utilização de agentes intermediários como consultores ou representantes comerciais;

IV - o setor do mercado em que atua;

$\mathrm{V}$ - os países em que atua, direta ou indiretamente;

VI - o grau de interação com o setor público e a importância de autorizações, licenças e permissões governamentais em suas operações;

VII - a quantidade e a localização das pessoas jurídicas que integram o grupo econômico e

VIII - o fato de ser qualificada como microempresa ou empresa de pequeno porte.

§2ㅇ A efetividade do programa de integridade em relação ao ato lesivo objeto de apuração será considerada para fins da avaliação de que trata o caput.

§3 $\mathrm{Na}$ avaliação de microempresas e empresas de pequeno porte serão reduzidas as formalidades dos parâmetros previstos neste artigo, não se exigindo, especificamente, os incisos III, V, IX, X, XIII, XIV e XV do caput.

$\S 4$ ㅇ Caberá ao ministro de Estado Chefe da Controladoria-Geral da União expedir orientações, normas e procedimentos complementares referentes à avaliação do programa de integridade de que trata este Capítulo.

$\S 5$ A redução dos parâmetros de avaliação para as microempresas e empresas de pequeno porte de que trata o §3으 poderá ser objeto de regulamentação por ato conjunto do ministro de Estado Chefe da Secretaria da Micro e Pequena Empresa e do ministro de Estado Chefe da Controladoria-Geral da União.
} 
De acordo com Batisti (2017, p. 105), a Lei n. 12.846/2013 promoveu uma mudança significativa no papel da empresa ao torná-la responsável por fiscalizar a conduta de seus colaboradores. A existência de canais de denúncia de irregularidades 3 é indispensável para o enfrentamento da corrupção.

\section{RESPONSABILIDADE EMPRESARIAL NO COMBATE À CORRUPÇÃO}

As empresas são responsáveis pela criação de instrumentos de prevenção às irregularidades, bem como por reprimir os atos praticados em desacordo com as leis, sob pena de responsabilização objetiva e imposição de sanções rigorosas previstas no artigo $19^{4}$ da Lei n. $12.846 / 2013$, aplicadas proporcionalmente às condutas praticadas.

Conforme Zanetti (2016, p. 47): “A principal novidade da Lei Anticorrupção foi estabelecer hipótese de responsabilidade objetiva para a pessoa jurídica envolvida em atos de corrupção". Antes do advento da referida legislação a responsabilidade por atos ilícitos, como regra, era subjetiva, ficando a objetiva como exceção, destaca a autora.

No mesmo sentido Batisti (2017, p. 76) assinala que:

A responsabilização objetiva das empresas pelas infrações descritas no art. $5^{\circ}$ é o aspecto mais inovador e controverso da Lei 12.846/2013. Isto porque a responsabilidade objetiva independe de dolo ou culpa. Assim, na Lei Anticorrupção, a causalidade decorrente do dolo é superada, e o nexo causal se dá a partir da relação de conduta e benefício procurado ou obtido pela pessoa jurídica.

A diferença está na necessidade de comprovação do dolo ou culpa pelo dano no caso da responsabilidade subjetiva, enquanto que na objetiva a lei a atribui independentemente da existência daqueles elementos. Embora a legislação impute às empresas a responsabilidade objetiva, a pessoa jurídica que arca com as consequências pode, posteriormente, apurar a responsabilização subjetiva de seus membros.

Conhecida também como Lei da Empresa Limpa, a Lei Anticorrupção brasileira preencheu uma lacuna legislativa consistente na responsabilização objetiva das pessoas jurídica, administrativa e judicial, que vão desde pesadas multas no âmbito administrativo, que podem chegar ao patamar de $20 \%$ sobre o faturamento bruto do ano anterior à prática da corrupção, até a extinção da empresa no âmbito judicial, além da proibição de transacionar com a administração pública por até cinco anos, e ter o nome da empresa incluído no Cnep - Cadastro Nacional de Empresas Punidas - e no Ceis - Cadastro de Empresas Inidôneas e Suspensas - o que significa, em muitos casos, a quebra da empresa (LUCHIONE; CARNEIRO, 2017, p. 84).

À pessoa jurídica envolvida em ilegalidade contra a administração pública são atribuídas as responsabilidades civil, penal e administrativa. Esta última é a que a Lei n. 12.846/2013 tornou mais severa em razão das pesadas sanções que expressamente prevê, como a multa sobre o faturamento bruto da empresa.

Segundo Silveira e Jorge (2019, p. 134), a lacuna legislativa preenchida pela Lei n. 12.846/2013 diz respeito: "[...] à ausência de meios específicos para atingir o patrimônio das pessoas jurídicas e obter efetivo ressarcimento dos prejuízos causados por atos que beneficiem a pessoa jurídica [...]". A imposição das sanções pecuniárias que a norma prevê pode acarretar a dissolução do negócio, dependendo da gravidade da situação na qual esteja envolvida a empresa.

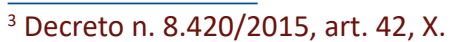

${ }^{4}$ Art. 19. Em razão da prática de atos previstos no art. 5o desta Lei, a União, os Estados, o Distrito Federal e os municípios, por meio das respectivas Advocacias Públicas ou órgãos de representação judicial, ou equivalentes, e o Ministério Público, poderão ajuizar ação com vistas à aplicação das seguintes sanções às pessoas jurídicas infratoras:

I - perdimento dos bens, direitos ou valores que representam vantagem ou proveito direta ou indiretamente obtidos da infração, ressalvado o direito do lesado ou de terceiro de boa-fé;

II - suspensão ou interdição parcial de suas atividades;

III - dissolução compulsória da pessoa jurídica;

IV - proibição de receber incentivos, subsídios, subvenções, doações ou empréstimos de órgãos ou entidades públicas e de instituições financeiras públicas ou controladas pelo poder público, pelo prazo mínimo de 1 (um) e máximo de 5 (cinco) anos.
} 
A Lei Anticorrupção aponta em seu artigo 5 quais atos são considerados na atribuição da responsabilidade objetiva empresarial ${ }^{5}$. Constata-se que tais atos refletem violação aos interesses públicos, o que exige uma postura inflexível por parte do poder público visando a desestimular a prática daqueles.

Conforme Luchione e Carneiro (2017, p. 85), as empresas ligadas a algum ato entre os previstos no artigo $5^{\circ}$ da Lei n. 12.846/2013 se enquadram na responsabilização objetiva, geralmente em razão de ilegalidades praticadas por membros da alta direção ou colaboradores, por meio de condutas ligadas à corrupção, fraudes e outras ilicitudes.

O conceito de corrupção é amplo, haja vista que sua existência é possível em situações diversificadas. Dependendo do viés pelo qual será analisada a interpretação e a classificação dos atos que a caracterizam, haverá variações, no entanto a essência é praticamente única, isto é, obter algum tipo de vantagem por meio da ilegalidade.

A compreensão de corrupção pode variar, dependendo da posição ideológica adotada. Numa visão mais tradicional e num sentido mais estrito, corrupção corresponde à oferta ou recebimento de benefícios ilícitos em razão de negócios entre agentes do setor público e particulares. Num sentido mais amplo, pode decorrer de relações entre particulares, como se dá quando um representante de empresa beneficia ilicitamente outro para conseguir vender produtos ou fornecer bens. Em um sentido ainda mais extenso, abrange comportamentos nas mais variadas esferas sociais, como nas atividades realizadas no regime de informalidade, na sonegação fiscal, no comércio ilegal, e ainda em outras situações tão comuns e banais (BATISTI, 2017, p. 29).

A descoberta do envolvimento de diversas empresas e seus gestores em casos de corrupção acendeu o alerta para a necessidade de serem tomadas medidas efetivas de combate à prática perpetrada por organizações criminosas em escala mundial. ${ }^{6}$ Diante disso, os países começaram a elaborar leis para o enfrentamento do problema.

De acordo com Coutinho (2018, p. 33): “Desde 2008, o combate à corrupção é tratado como política legislativa global, por consequência da crise econômica por que passaram os países desenvolvidos". A situação ocorrida naquele ano no plano internacional deu impulso à elaboração de normas anticorrupção em diversos países.

A globalização contribuiu sobremaneira para a intensificação da corrupção e, a partir daí pressões internacionais impulsionaram a internalização de diversos instrumentos normativos no ordenamento jurídico brasileiro. A manutenção das regras de mercado leais e transparentes a nível global passou a ser uma preocupação dos organismos supranacionais, dando origem a tratados ratificados pelo Brasil (BATISTI, 2017, p. 48).

\footnotetext{
5 Art. 50 Constituem atos lesivos à administração pública, nacional ou estrangeira, para os fins desta Lei, todos aqueles praticados pelas pessoas jurídicas mencionadas no parágrafo único do art. 1ำ, que atentem contra o patrimônio público nacional ou estrangeiro, contra os princípios da administração pública ou contra os compromissos internacionais assumidos pelo Brasil, assim definidos:

I - prometer, oferecer ou dar, direta ou indiretamente, vantagem indevida a agente público, ou a terceira pessoa a ele relacionada;

II - comprovadamente, financiar, custear, patrocinar ou de qualquer modo subvencionar a prática dos atos ilícitos previstos nesta Lei;

III - comprovadamente, utilizar-se de interposta pessoa física ou jurídica para ocultar ou dissimular seus reais interesses ou a identidade dos beneficiários dos atos praticados;

IV - no tocante a licitações e contratos:

a) frustrar ou fraudar, mediante ajuste, combinação ou qualquer outro expediente, o caráter competitivo de procedimento licitatório público;

b) impedir, perturbar ou fraudar a realização de qualquer ato de procedimento licitatório público;

c) afastar ou procurar afastar licitante, por meio de fraude ou oferecimento de vantagem de qualquer tipo;

d) fraudar licitação pública ou contrato dela decorrente;

e) criar, de modo fraudulento ou irregular, pessoa jurídica para participar de licitação pública ou celebrar contrato administrativo;

f) obter vantagem ou benefício indevido, de modo fraudulento, de modificações ou prorrogações de contratos celebrados com a administração pública, sem autorização em lei, no ato convocatório da licitação pública ou nos respectivos instrumentos contratuais; ou

g) manipular ou fraudar o equilíbrio econômico-financeiro dos contratos celebrados com a administração pública;

V - dificultar atividade de investigação ou fiscalização de órgãos, entidades ou agentes públicos, ou intervir em sua atuação, inclusive no âmbito das agências reguladoras e dos órgãos de fiscalização do sistema financeiro nacional.

6 Empreendimentos transnacionais atuantes em setores como a construção civil, exploração de petróleo e seus derivados, entre outros, foram alvos de ampla investigação.
} 
A criação da Lei 12.846/13 é resultante da pressão internacional sobre o Brasil, que havia se comprometido a combater a corrupção ao assinar documentos internacionais, tais como: Convenção das Nações Unidas Contra a Corrupção (2003), Convenção Interamericana Contra a Corrupção (1996) e Convenção da Organização para a Cooperação Econômica e o Desenvolvimento - OCDE (1997).

Desse modo, visando a cumprir os compromissos firmados, criaram-se mecanismos legais para a responsabilização das pessoas jurídicas pelos atos de corrupção que envolvem transações comerciais com outros países. O compliance incide, portanto, na relação da pessoa jurídica privada com a administração pública brasileira ou com a estrangeira.

Silva (2018, p. 84) observa que a Lei n. 12.846/2013 não é a primeira legislação nacional a disciplinar a questão, mas com o advento da referida norma as sanções para as empresas que participam de situações de corrupção com a administração pública tornaram-se mais severas nas searas não penais.

De fato, a norma anticorrupção tem produzido resultados relevantes no enfrentamento da corrupção empresarial no Brasil. A Controladoria Geral da União (CGU) divulgou em seu site ${ }^{7}$ que no ano de 2018 foram aplicadas pelo governo federal cerca de 30 penalidades baseadas na Lei Anticorrupção.

O compliance tem como pilares, segundo Coutinho (2018, p. 51-52): “(1) Comprometimento e apoio da Alta Administração; (2) Instância responsável pelo Programa de Integridade; (3) Análise de perfil e riscos; (4) Estrutura das regras e instrumentos; e (5) Estratégias de Monitoramento contínuo".

Verifica-se que o programa de integridade dever ser praticado em todas as áreas da empresa com foco voltado para os riscos. Por essa razão a existência de um Código de Conduta e Ética mostra-se imprescindível para a avaliação das condutas, verificando-se se estão em conformidade com as leis.

\section{O COMPLIANCE COMO FERRAMENTA PARA A REDUÇÃO DA CORRUPÇÃO}

Por meio de procedimentos internos de controle as empresas podem diminuir a ocorrência de condutas em desacordo com as normas, bem como impedir que sejam praticadas, isto é, de modo preventivo evitar a transgressão das leis pela redução de riscos relacionados à áreas de atuação do negócio.

O compliance pode ser considerado uma ferramenta eficaz para a redução da corrupção por destacar a importância da ética empresarial e pela atribuição de responsabilidade objetiva para as pessoas jurídicas de Direito privado sob pena de incorrerem em sanções administrativas severas.

O compliance tem objetivos tanto preventivos como reativos. Visa à prevenção de infrações legais em geral assim como a prevenção dos riscos legais e reputacionais aos quais a empresa está sujeita, na hipótese de que essas infrações se concretizem. Além disso, impõe à empresa o dever de apurar as condutas ilícitas em geral, assim como as que violam as normas da empresa, além de adotar medidas corretivas e entregar os resultados de investigações internas às autoridades, quando for o caso (VERÍSSIMO, 2017, p. 91).

A partir do viés preventivo infere-se que a empresa afasta a ocorrência das ilegalidades, preservando-se de incorrer em responsabilidade objetiva e obrigação de reparação de danos causados por tais atos. Como instrumento reativo o compliance possibilita que a pessoa jurídica recupere os prejuízos sofridos pela identificação do(s) autor(es) da conduta ilegal.

Para Zanetti (2016, p. 51): "Os programas de integridade ou programas de "compliance" se revelam ferramentas úteis para auxiliar os procedimentos de controle e gestão de riscos das empresas". O ponto principal do compliance é a gestão dos riscos, visando a prevenir ou corrigir sua existência em meio ao empreendimento que adota o mecanismo.

Silveira e Jorge (2019, p. 129) destacam os principais objetivos do compliance:

Compliance possui, entre os seus objetivos, organizar documentação e procedimentos, gerenciando de forma adequada os riscos e exaltando a transparência, de alcance amplo e não apenas cumprimento de regras formais ou informais. Está ligado ao conceito de "governança corporativa", ou seja, de sistemas de organização

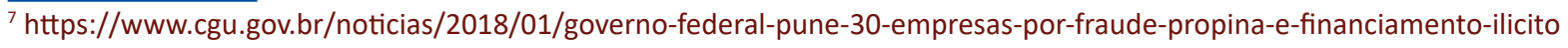


empresarial, tendo como um dos objetivos diminuir a responsabilidade objetiva da empresa, utilizado para contenção de riscos, com o comprometimento da empresa no cumprimento da legislação em vigor, a partir de procedimentos internos que visam uma maior transparência em seus atos e decisões.

Embora a elaboração de programas de integridade no âmbito interno das pessoas jurídicas seja vantajosa, ocorre um acréscimo considerável de despesa para a empresa. Batisti $(2017$, p. 87) aponta que: "A implementação de um programa de compliance bem estruturado e a busca pela mudança de uma cultura organizacional pode ser um processo que consome inúmeros recursos em termos de tempo, finanças e capital humano".

A realização de treinamentos periodicamente, bem como o monitoramento contínuo, por exemplo, podem demandar investimento financeiro elevado, dependendo da dimensão estrutural do empreendimento, ou seja, da quantidade de integrantes que o compõem. Além disso, os procedimentos que caracterizam um programa de integridade envolvem deveres que consomem tempo e capital humano.

As vantagens auferidas com a prática do compliance, contudo, podem compensar o investimento da empresa. Para Moreira (2018),

[...] eliminar o "risco de compliance" consiste também em eliminar o risco de sanções regulatórias, de perda financeira ou perda de reputação, que uma organização pode sofrer como resultado de falhas no cumprimento de leis, regulamentações, códigos de conduta e das boas práticas.

As multas previstas na Lei $n$. 12.846/2013 podem desequilibrar a situação financeira da empresa dependendo do valor que alcancem, porém a perda da reputação pode significar um prejuízo maior, uma vez que a confiança de parceiros comerciais e clientes, bem como da administração pública, se reduzirá, ensejando o enfraquecimento da atividade e de seus ganhos.

Constata-se, dessa maneira, que o compliance contribui para a existência de probidade no empreendimento, protegendo a pessoa jurídica que adota o programa de integridade contra os efeitos nocivos da corrupção. Ademais, caso seja constatada a existência de irregularidade é possível atenuar as sanções legais.

Na elaboração do mecanismo em análise Batisti (2017, p. 114) recomenda que: "Em face do desafio do controle da corrupção para fins de reduzir as sanções administrativas e judiciais, é importante que os paradigmas legais sejam considerados para a construção de programas de integridade".

Não há um modelo padrão a ser seguido para a elaboração do programa de integridade. Existem, todavia, elementos essenciais para caracterizar o compliance: mecanismos e procedimentos internos de integridade, auditoria e incentivo à denúncia de irregularidades e aplicação de códigos de ética e de conduta, políticas e diretrizes para se detectar e sanar desvios, fraudes, irregularidades e atos ilícitos praticados contra a administração pública nacional ou estrangeira. ${ }^{8}$

Diante disso, questiona-se: Como as empresas brasileiras estão construindo seus programas de integridade e colocando-os em execução? Para responder à indagação são relacionadas algumas empresas de modo exemplificativo.

\section{EMPREENDIMENTOS NACIONAIS QUE POSSUEM PROGRAMA DE INTEGRIDADE}

A Votorantim S.A . iniciou em 2006 o processo de estabelecimento de um programa de compliance. Entre as medidas tomadas houve a elaboração de um material (cartilha) destinado a todos os colaboradores da empresa, no qual se encontram esclarecimentos acerca do referido programa..$^{9}$ Além disso, o grupo empresarial dispõe de Código de Conduta, Programa Anticorrupção, Linha Ética e Auditoria Interna, acessíveis a quaisquer interessados, no site do empreendimento. ${ }^{10}$

\footnotetext{
${ }^{8}$ Decreto n. 8.420/2015, artigo 41.

${ }^{9} \mathrm{http}: / /$ www.votorantim.com.br/assets/public/files/01_cartilha_de_compliance.pdf

${ }^{10} \mathrm{http}: / /$ www.votorantim.com.br/
} 
A Goodman Brasil Logística S.A. destaca em seu manual de compliance e controles internos ${ }^{11}$ a indispensabilidade do cumprimento das leis e regras de ordem interna da empresa por todos os colaboradores que nela trabalham. Exige-se também a responsabilidade profissional de cada indivíduo em relação a todos os serviços e atividades que realizar.

A Gerdau S.A. dispõe de canais de comunicação (on-line, via telefone e presencial) ${ }^{12}$ para que sejam reportados incidentes éticos e esclarecimentos de dúvidas. Além do Código de Ética para seus colaboradores, a empresa possui um Código de Ética para Terceiros e Política de Compliance.

A Camargo Côrrea Infra ${ }^{13}$ possui um modelo de compliance amplo, sendo composto por: Comitê de Ética e Conduta, Comitê de Auditoria, Comitê de Estratégia e Sustentabilidade, Comitê Financeiro e Riscos, Comitê de Pessoas e Comitê de Propostas/Técnico. Esses comitês estão ligados ao Conselho de Administração, que por sua vez, encontra-se relacionado à Presidência da empresa. Além disso, há Diretorias responsáveis por áreas específicas: Executivo de Operações, Executivo Jurídico, Integridade e Comunicação Corporativa, Executivo de Finanças, Executivo Comercial e de Novos Negócios, Recursos Humanos e Auditoria e Riscos.

Observa-se nos exemplos antes transcritos que cada pessoa jurídica formulou seu programa de integridade com base nas disposições legais, mas também considerando suas necessidades. Algumas adotam modelos mais amplos do que outras em razão da dimensão de sua estrutura interna e pela atividade que desenvolve.

\section{CONSIDERAÇÕES FINAIS}

Verificou-se que a responsabilidade das empresas no Brasil passou a ser objetiva a partir do advento da Lei n. 12.846/2013, com o destaque conferido ao compliance como forma de combate à corrupção empresarial, por meio da prevenção às condutas que culminem com a inobservância das normas e suas consequências danosas.

Identificou-se na Lei Anticorrupção normas rígidas que para sua observância podem elevar os custos operacionais do negócio, mas constatou-se também que o investimento em um programa de integridade pode evitar que sanções rigorosas desestabilizem financeiramente a empresa, o que pode prejudicar a continuidade de sua atividade, conforme o caso.

Detectou-se que a existência do compliance tornou-se imprescindível para o enfrentamento eficaz da corrupção empresarial, podendo atenuar as consequências legais da existência de irregularidades no âmbito interno da empresa, uma vez que possui viés preventivo e reativo.

Diagnosticou-se que a aplicação da legislação tem produzido os resultados esperados, isto é, diversas empresas que vinham atuando em prejuízo da administração pública estão recebendo as sanções legais, como demonstra a Controladoria Geral da União (CGU).

Destacaram-se os objetivos do compliance e de que maneira estes contribuem para preservar a reputação das empresas, mantendo com isso a confiabilidade dos interessados na contratação das atividades realizadas pelo empreendimento.

Observaram-se alguns exemplos práticos de aplicação de programas de integridade em empresas nacionais. Inferiu-se que não há um modelo padrão de compliance a ser posto em prática pelas pessoas jurídicas de Direito privado, mas a legislação destaca elementos essenciais para a caracterização do mecanismo em análise.

Conclui-se que as empresas são responsáveis por combater a corrupção no âmbito interno de seus estabelecimentos, envolvendo todos os indivíduos que atuam diretamente em suas atividades.

O legislador brasileiro deu importante passo no cumprimento dos compromissos internacionais assumidos pelo país para o combate à corrupção com a positivação da Lei Anticorrupção.

\footnotetext{
${ }^{11} \mathrm{https} / / /$ br.goodman.com/-/media/Files/Sites/Brazil/Investment-management/Policies/Manual-de-Compliance.pdf?la=pt-BR\&hash=90AA 8507ABE5BE879BD1333DB82479A3A7C32063

12 https://www2.gerdau.com.br/sobre-nos/canal-da-etica

${ }^{13} \mathrm{https}: / /$ camargocorreainfra.com/wp-content/uploads/2019/09/Apresenta\%C3\%A7\%C3\%A3o-Institucional-CCINFRA-Portugu\%C3\%AAs_29-08-19.pdf
} 


\section{REFERÊNCIAS}

BATISTI, B. M. Compliance e corrupção: análise de risco e prevenção nas empresas em face dos negócios públicos. Curitiba: Juruá, 2017.

BLOK, M. Compliance e governança corporativa: atualizado de acordo com a Lei Anticorrupção Brasileira (Lei 12.846) e o Decreto-Lei 8.421/2015. Rio de Janeiro: Freitas Bastos, 2017.

COUTINHO, L. M. Compliance anticorrupção, a Lei das estatais e a defesa do Estado Democrático de Direito. Rio de Janeiro: Lumen Juris, 2018.

LUCHIONE, C. H.; CARNEIRO, C. Compliance e Lei anticorrupção - importância de um programa de integridade no âmbito corporativo e setor público. In: PORTO, V.; MARQUES, J. (org.). O compliance como instrumento de prevenção e combate à corrupção. Porto Alegre: Livraria do Advogado, 2017.

MOREIRA, E. O. Compliance no Brasil: aspectos da responsabilidade fiscal das empresas no combate à corrupção. Revista Jurídica da Escola Superior de Advocacia da OAB-PR, ano 3, n. 2, ago. 2018. Disponível em: http://revistajuridica.esa.oabpr.org.br/ compliance-no-brasil-aspectos-da-responsabilidade-fiscal-das-empresas-no-combate-a-corrupc\%CC\%A7a\%CC\%83o/. Acesso em: 3 nov. 2019.

PASOLD JÚNIOR, C. L. Corrupção: um dos pilares da insegurança jurídica no desenvolvimento empresarial nacional. In: PORTO, V.; MARQUES, J. (org.). O compliance como instrumento de prevenção e combate à corrupção. Porto Alegre: Livraria do Advogado, 2017.

RIBEIRO, M. C. P.; DINIZ, P. D. F. Compliance e Lei anticorrupção nas empresas. Revista de Informação Legis/ativa, ano 52, n. 205 jan./mar. 2015, p. 87-105. Disponível em: https://www12.senado.leg.br/ril/edicoes/52/205/ril_v52_n205_p87. Acesso em: 2 nov. 2018.

SILVA, R. C. Acordo de Leniência e Compliance: perspectivas no enfrentamento da corrupção empresarial. 2018. Dissertação (Mestrado em Direito. Tutelas à Efetivação de Direitos Indisponíveis. Tutelas à Efetivação de Direitos Públicos Incondicionados) - Fundação Escola Superior do Ministério Público, Porto Alegre,. 2018.

SILVEIRA, D. B.; JORGE, C. H. M. O compliance e seus reflexos no direito brasileiro. Revista Scientia Juris, Londrina, PR, v. 23, n. 1, p. 125-143, mar. 2019. Disponível em: http://www.uel.br/revistas/uel/index.php/iuris/article/view/34612. Acesso em: 30 out. 2019.

UBALDO, F. S. Lei Anticorrupção: a importância do programa de compliance no cenário atual. In: PORTO, Vinícius; MARQUES, Jader (org.). O compliance como instrumento de prevenção e combate à corrupção. Porto Alegre: Livraria do Advogado, 2017.

VERÍSSIMO, C. Compliance: incentivo à adoção de medidas anticorrupção. São Paulo: Saraiva, 2017.

ZANETTI, A. F. Lei anticorrupção e compliance. Revista Brasileira de Estudos da Função Pública, Belo Horizonte, ano 5, n. 15, set./dez. 2016, p. 35-60. Disponível em: https://www.editoraforum.com.br/wp-content/uploads/2017/03/lei-anticorrupcao-compliance-artigo.pdf. Acesso em: 25 mar. 2018. 